\title{
SOME NUMERICAL RESULTS ON THE PARAMETER IDENTIFICATION PROBLEM FOR THE HEAT CONDUCTION EQUATION
}

WERNER NEUNDORF

Institute of Technology, 6300 Ilmenau, GDR

\section{Introduction}

The parameter identification problem is known also as the inverse problem.

Some experimental investigations are described in [1] and one can find theoretical results by A. D. Iskenderov, R. J. Lermit, J. W. Mosevich, B. F. Jones, A. V. Balakrishnan, G. I. Marchuls and others. There exist many different ways of approach.

Suppose the values of the solution of the heat conduction equation have been measured at discretc points in time and space (discrete observation). The continuous dependence of the nndetermined coefficients on the data and the region is proven for this partial differential equation.

The problem of determination or identification of the parameters of a solid arises in course of the development of new solids in the glass, ceramic or steel industry.

\section{The ordinary differential equation as an illustration}

The simple and well known growth problem of a population is defined by the ordinary differential equation

$$
y^{\prime}(t)=c y(t), \quad y(0)=y_{0}>0, \quad 0 \leqslant l \leqslant T,
$$

where a sequence $\left\{y_{i}\right\}_{i=0}^{N}$ of measured data (an observed solution) $y_{i}=y\left(t_{i}\right)$, $0=t_{0}<t_{1}<\ldots<t_{N}=T$, is given and the constant $c$ is unknown. The solution of (1) is

$$
y(t)=y_{0} \exp (c t)
$$


First let us discuss some possibilities of evaluating $c$ :

1. The analytic solution for the value of $c$ is

$$
c=c(t)=\frac{1}{t} \ln \frac{y(t)}{y_{0}} .
$$

Assume a specific value for $t$; we ignore many other points because of the general situation $c\left(t_{i}\right) \neq c\left(t_{j}\right)$ for $i \neq j$.

2. The assumption

$$
c=\frac{y^{\prime}(t)}{y(t)} \approx \frac{y\left(t_{i+1}\right)-y\left(t_{i}\right)}{\Delta t_{i} \cdot y\left(t_{i}\right)}
$$

is also very poor since numerical differentiation is required. We must again chooso a specific $t$.

3. The following consideration based on the equivalent integral equation

$$
y(t)=y_{0}+c \int_{0}^{t} y(x) d x
$$

supplies a better approximation

$$
c=\frac{y(t)-y_{0}}{\int_{0}^{t} y(x) d x}
$$

4. The best approximation for $c$ based on all values $y_{i}$ is obtained by the following

$$
\begin{gathered}
y^{\prime}=c y \\
\int_{0}^{t} y^{\prime}(x) d x=c \int_{0}^{t} y(x) d x \\
\int_{0}^{T}\left(y(t)-y_{0}\right) d t=\int_{0}^{T} \int_{0}^{t} y^{\prime}(x) d x d t=0 \int_{0}^{T} \int_{0}^{t} y(x) d x d t \\
=0 \int_{0}^{T}(T-x) y(x) d x, \\
c=\int_{0}^{T}\left(y(t)-y_{0}\right) d t / \int_{0}^{T}(T-t) y(t) d t
\end{gathered}
$$

which requires moro computing expense. 
All these cases show the difficulties arising in the solution of this simple inverse problem.

\section{The heat conduction equation}

Let us consider a solid given as a full infinite cylinder, and assume that we lave the possibility to measure the temperature $\bar{T}(x, t)$ at points $\left(\bar{r}_{i}, \bar{t}_{j}\right)$ belonging to the set

$$
\begin{array}{r}
G_{\mathrm{meg}}=\left\{\left(\bar{r}_{i}, \bar{t}_{j}\right): i=0,1, \ldots, r_{m}, 0 \leqslant \bar{r}_{0}<\bar{r}_{1}<\ldots<\bar{r}_{r_{m}} ;\right. \\
j=0,1, \ldots, t_{m}, \bar{t}_{j}=j \cdot Z / t_{m} \text { (equidistant), } Z-\text { whole } \\
\text { time of measurement }\} .
\end{array}
$$

The solid is homogeneous, isotropic and without heat sources.

We consider the temperature as a solution of the one-dimensional heat conduction equation in an infinite cylinder with the radius $R=\bar{r}_{r_{m}}$. This parabolic initial-boundary value problem has the form

$$
(c \varrho)(T) \frac{\partial T}{\partial t}=\frac{1}{r} \frac{\partial}{\partial r}\left(r \cdot \lambda(T) \frac{\partial T}{\partial r}\right)
$$

in the bounded domain $G=\{(r, t): 0<r<R, 0<t \leqslant Z\} \subset \boldsymbol{R}^{2}$ with

$$
\begin{aligned}
& T(r, 0)=u_{0}(r), \quad 0 \leqslant r \leqslant R \quad \text { (initial condition), } \\
& \left.\frac{\partial T}{\partial r}\right|_{r=0}=0, \\
& T(R, t)=\varphi_{1}(t),
\end{aligned}
$$

where the coefficients, the heat conductivity $\lambda$, the density $\varrho$, the specific heat $c$ and the heat capacity per unit volume $c \varrho$ are positive. Either $c \varrho$ or $\lambda$ is the unknown function of $T$.

\section{The identification algorithm}

Analyzing this problem numerically, we assume the following step algorithm:

1. Approximation to the I.C. $u_{0}(v)$ using the values $\bar{T}\left(\bar{r}_{i}, 0\right)$ :

- manual, e.g. with cubic splines,

- by the Newton interpolation polynomial of degree $k=r_{m} \leqslant 4$, 
- by the least squares method using polynomials of degree $k$ $\leqslant \min \left(4, r_{m}\right)$.

2. Approximation to the B.O. $\varphi_{1}(t)$ using the values $\bar{T}\left(R, t_{j}\right)$ :

- manual,

- by the piecewise-lincar function (a polygonal line) through the values $\bar{T}\left(R, t_{j}\right)$,

- by the least squares method using polynomials (of degree $\%$ $\left.\leqslant \min \left(4, t_{m}\right)\right)$ or the exponential function $(b \cdot \exp (d t))$.

3. Solution of (9)-(11) with use of a finite difference method assuming the equidistant mesh

$$
\begin{aligned}
G_{l b}=\left\{\left(r_{i}, t_{j}\right): r_{i}=i \cdot h, h\right. & =R / N_{r} \text { spatial step size; } \\
t_{j} & \left.=j \cdot \tau, \tau=Z / N_{l} \text { temporal step sizc }\right\}
\end{aligned}
$$

such that $N_{i} / t_{m}$ and $\left(\bar{r}_{i+1}-\bar{r}_{i}\right) / h$ are integers. Then we have $G_{\text {mes }} \subset G_{h} \subset \bar{G}$.

We seelr either ce or $\lambda$ in the form

$$
\sum_{i=1}^{n} a_{i} T^{i-1}, \quad \text { where } n \leqslant 7
$$

The following difference schemes are possible:

- explicit method,

- implicit linearized method (chase method; progonka (Russ.)),

- implicit itcrative method,

- Oranle-Nicolson linearized,

- Crantr-Nicolson iterative.

4. Computation of the functional

$$
E\left(a_{1}, a_{2}, \ldots, a_{n}\right)=\sum_{i=0}^{r_{m}} \sum_{j=0}^{\iota_{m}}\left(\bar{T}\left(\bar{r}_{i}, \bar{t}_{j}\right)-T\left(\bar{r}_{i}, \bar{t}_{j}\right)\right)^{2}
$$

and its minimization by a gradient-like method

$$
a^{(m+1)}=a^{(m)}+p_{m} \cdot s^{(m)}, \quad m=0,1, \ldots ; a^{(0)} \text { given },
$$

with the finite difference approximation of the Jacobian matrix, i.e.

$$
s^{(m)}=-J E\left(a^{(m)}\right) \quad \text { (steepest descent step) }
$$

or the Hessian matrix, i.e.

$$
s^{(m)}=-H^{-1} J E\left(a^{(m)}\right) \quad \text { (Newton step). }
$$


There exists a computer test program in PL/1 and ALGOL 1204 with some additional refinements.

\section{Numerical examples}

We have tested the algorithm on the ES 1040 computer in double precision on several test problems of varying character and difficulty.

Test problem 1. For a eslindrical solid we have measured 6 different temperature fields $\bar{T}_{i}$ by cooling and/or heating, with $\nu_{0}(r)=$ constant. The parameters are given in Table 1 :

Table 1

\begin{tabular}{|l|c|c|c|c|c|c|c|c|}
\hline & $r_{m}$ & $i_{m}$ & $\begin{array}{c}R=\bar{r}_{r_{m}} \\
(\mathrm{~m})\end{array}$ & $\begin{array}{c}Z \\
(\mathrm{l})\end{array}$ & $\bar{r}_{0}$ & $\bar{r}_{1}$ & $\bar{r}_{\mathrm{a}}$ & $\overline{\bar{r}}_{3}$ \\
\hline $\bar{T}_{1}, \bar{T}_{2}$ & 3 & 60 & .030 & $1 / 2$ & .014 & .023 & .026 & .03 \\
$\bar{T}_{3}, \bar{T}_{4}, \bar{T}_{\mathrm{b}}$ & 3 & 40 & .030 & $1 / 3$ & .014 & .023 & .026 & .03 \\
$\bar{T}_{\mathrm{b}}$ & 2 & 30 & .030 & $1 / 4$ & .014 & .026 & .030 & \\
\hline
\end{tabular}

The coefficient c 0 is equal to 720 and we seck the constant function $\lambda=a_{1}$. The algorithm applies the least squares method using polynomials of degree $F_{i}=0$ for $u_{0}(r)$, the polygonal lines for $\varphi_{1}(t)$ and the difference method "C-N linearized" with the grid size $30 \times t_{m}$. For each example the minimization process is convergent for arbitrary nonnegative start point $a_{1}^{(0)}$ and computes 6 values of $a_{1}$ and the average deviation $\dot{D}=\operatorname{sqrt}\left(\frac{1}{\left(r_{m}+1\right)\left(t_{m}+1\right)} \cdot E\left(a_{1}\right)\right)$, as shown in Table 2:

Table 2

\begin{tabular}{|l|c|c|c|c|c|c|c|}
\hline & $\bar{T}_{1}$ & $\bar{T}_{2}$ & $\bar{T}_{3}$ & $\bar{T}_{4}$ & $\bar{T}_{5}$ & $\bar{T}_{\mathrm{a}}$ & $\begin{array}{l}\text { first } 1 / 2 \\
\text { part } \bar{T}_{2}\end{array}$ \\
\hline $\begin{array}{l}a_{1} \\
D\left(^{\circ}\right)\end{array}$ & $\begin{array}{l}1.172 \\
2.2\end{array}$ & $\begin{array}{l}1.264 \\
0.4\end{array}$ & $\begin{array}{l}1.186 \\
1.9\end{array}$ & $\begin{array}{l}1.258 \\
1.4\end{array}$ & $\begin{array}{l}1.354 \\
1.2\end{array}$ & $\begin{array}{l}1.213 \\
1.0\end{array}$ & $\begin{array}{l}1.240 \\
8.3\end{array}$ \\
\hline
\end{tabular}

All measured temperatures belong to the interval $\left(83^{\circ}, 441^{\circ}\right)$.

Test problem 2. A temperature field $\bar{T}$ was generated by the program itself and then we have tried to identify the values carrying out the minimization (15) with different start vectors $a^{(0)}$. 
The parameters and data for gencration are

$$
\begin{array}{rlrl}
R & =\bar{r}_{r_{m}}=0.030 \mathrm{~m}, & c \varrho & =720, \\
\lambda & =1.2, \\
Z=0.25 \mathrm{~h}, & \iota_{0}(r) & =342, \\
r_{m}=3, & \varphi_{1}(t) & =312 \cdot \exp (-t), \\
t_{m} & =30, & \bar{r}_{0} & =0, \\
N_{r} & =10, & \bar{r}_{1} & =0.015, \\
N_{t} & =30, & \bar{r}_{2} & =0.024, \\
\text { "C-N linearized", } & \bar{r}_{3} & =0.030 .
\end{array}
$$

The function $\lambda=1.2$ is our unlrnown.

Variant 1: $n=1$. The algorithm is convergent for every start point $a_{1}^{(0)} \geqslant 0$ and also for $a_{1}^{(0)}<0$, while we do not compute number overflow, see Fig. 1. The numerical investigation underlines the existence

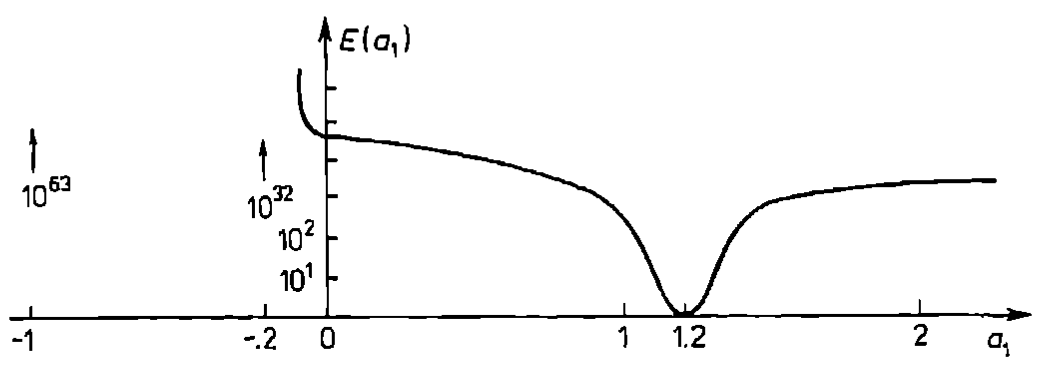

Fig. I. The function $E\left(a_{1}\right)$

and uniqueness of solution (a constant positive value) and the convergence of minimization process to this constant.

Variant 2: $n=2$. Figures 2 and 3 show the domain of convergence of the minimization algorithm lying above the curve

$$
a_{2}=-3 \cdot 10^{-3} a_{1}-10^{-3}
$$

In other domains the coefficient $\lambda=a_{1}+a_{2} T, 0 \leqslant T \leqslant 342$, is very negative, and hence not allowed in equation (9). This is also the case of a great deal of extrema. Choosing a start rector $a^{(0)}$ in this domain we cannot expect, in general, a descent process to the absolute minimum. 


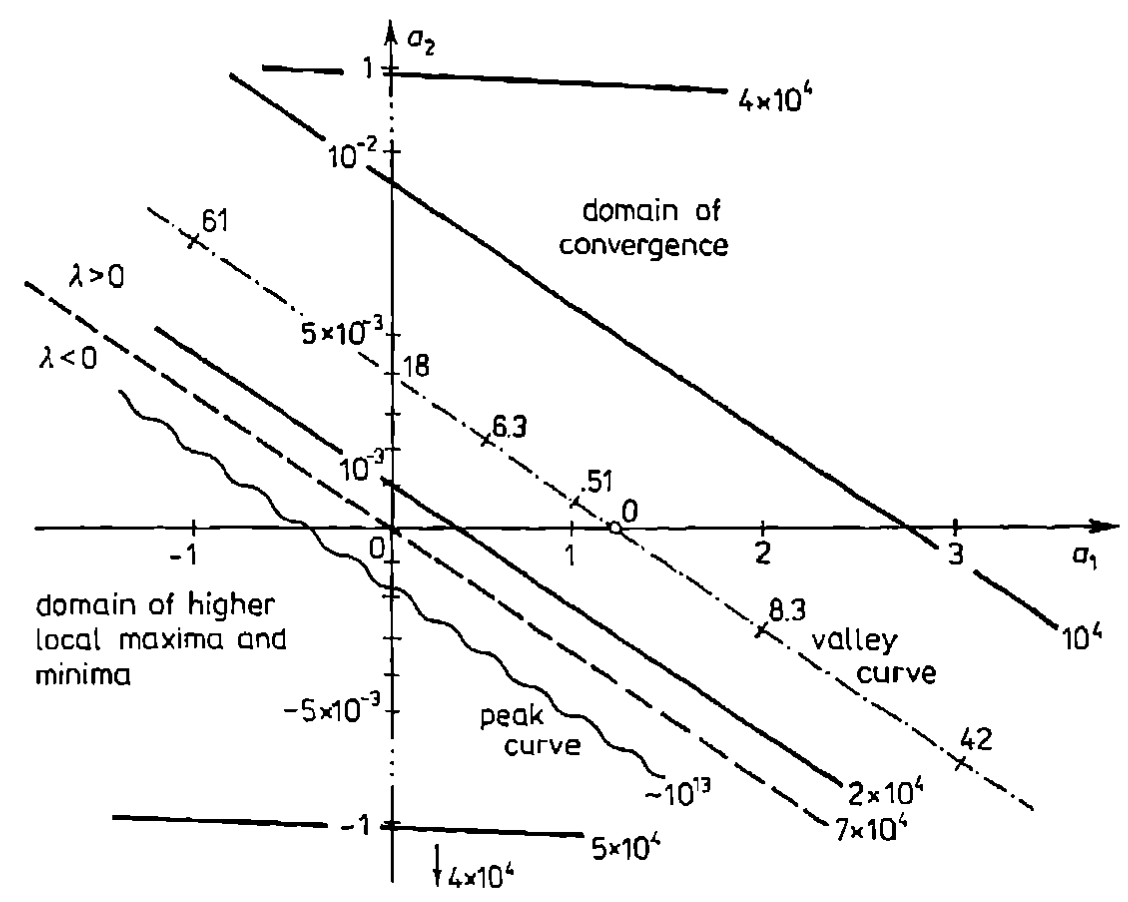

Fig. 2. Level curves of the function $E\left(a_{1}, a_{2}\right)$

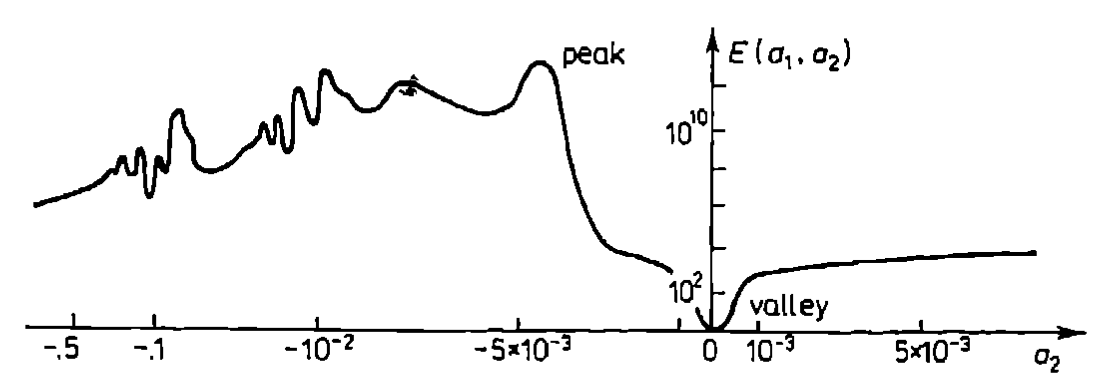

Fig. 3. The function $E\left(a_{1}, a_{2}\right)$ with the constant component $a_{1}=1.2$

The examples given in Table 3 show the good quality and performance of the procedure.

For the computation of the value $E(a)$ we must always solve the problem (9)-(11), (16) approximatively. The computing time is about 120 sec and belongs for all tests to the interval $F^{\prime}(1,1.2)$, where $F$ is the last number in the 4 th column of Table 3 , here $80+2 \cdot 9=104$.

Table 4. shows that we can obtain convergence in spite of an unfavourable choice of the start vector. In the second part of this table wo illustrate the minimization process if $a_{1}=$ constant. The algorithm is very slow if the component $a_{2}$ lies far away from the valley curve in the positive direction. 
Also in this case the existence and uniqueness scem to be guaranteed under additional conditions on the coefficient functions, I.C. and/or B.C.

Table 3

\begin{tabular}{|c|cccl|}
\hline$N$ & $\lambda=a_{1}$ & \multicolumn{1}{c}{$a_{2} \cdot T$} & $F$ & $E(a)$ \\
\hline 0 & .5 & .0 & 1 & $1.16 \mathrm{E} 4$ \\
1 & .50002030 & .00646648 & 5 & $7.74 \mathrm{E} 3$ \\
2 & -16.5988271 & .06034097 & 20 & $4.77 \mathrm{E} 3$ \\
3 & -13.0407149 & .04623392 & 31 & $2.41 \mathrm{E} 3$ \\
4 & -13.0407127 & .04683369 & 43 & $2.37 \mathrm{E} 3$ \\
5 & -.96638062 & .00019034 & 57 & $4.40 \mathrm{E} 2$ \\
6 & -2.05446040 & .01034211 & 66 & $1.43 \mathrm{E} 2$ \\
7 & 1.18036579 & .00007479 & 77 & $1.80 \mathrm{E}-1$ \\
8 & 1.20233812 & -.00000741 & 82 & $7.27 \mathrm{E}-5$ \\
9 & 1.20076385 & -.00000230 & $86+2 \cdot 9$ & $3.05 \mathrm{E}-5$ \\
\hline
\end{tabular}

$N$ - number of iteration, $F$ - number of evaluations of the function $E(a)$

Table 4

\begin{tabular}{|r|rrrl|}
\hline$N$ & \multicolumn{1}{r}{$\lambda=a_{1}$} & \multicolumn{1}{c}{$a_{2} \cdot T$} & \multicolumn{1}{c}{$F$} & \multicolumn{1}{c}{$E(a)$} \\
\hline 0 & 1.2 & -.01 & 1 & $3.25 \mathrm{E} 11$ \\
1 & 1.22332787 & .02024551 & 5 & $2.68 \mathrm{E} 4$ \\
2 & 1.24202062 & .00582810 & 15 & $1.14 \mathrm{E} 4$ \\
$\ldots$ & & & & \\
4 & 8.78147573 & -.02394664 & 36 & $8.12 \mathrm{E} 2$ \\
$\ldots$ & & & & \\
6 & 4.06047108 & -.00938961 & 68 & $2.46 \mathrm{E} 2$ \\
7 & 1.45832575 & -.00079787 & 79 & $1.67 \mathrm{E} 0$ \\
8 & 1.20655343 & -.00002157 & 85 & $1.07 \mathrm{E}-3$ \\
9 & 1.19888587 & .00000335 & 90 & $6.47 \mathrm{E}-5$ \\
$\ldots$ & & & & \\
18 & 1.20090873 & -.00000294 & 128 & $1.23 \mathrm{E}-5$ \\
$\ldots$ & & & & \\
177 & 1.20075754 & -.00000242 & 3551 & $7.37 \mathrm{E}-6$ \\
\hline 0 & 1.2 & -.01 & 1 & $3.25 \mathrm{E} 11$ \\
1 & 1.2 & .02819660 & 5 & $3.02 \mathrm{E} 4$ \\
2 & 1.2 & .02656007 & 17 & $2.97 \mathrm{E} 4$ \\
3 & 1.2 & .01970204 & 21 & $2.02 \mathrm{E} 4$ \\
\hline
\end{tabular}

Variant $3: n=3$. We obtain no convergence (or, maybe, very slow convergence) also for $a^{(0)} \approx 1.2$, as can be shown not only by the following examples. 
Table 5

\begin{tabular}{|c|c|c|c|c|c|}
\hline$N$ & $\lambda=a_{1}$ & $a_{2} \cdot T+$ & $a_{3} \cdot T^{2}$ & $F$ & $E(a)$ \\
\hline 0 & 1.15 & .0 & .0 & 1 & $3.17 \mathrm{E} 1$ \\
\hline$\dddot{21}$ & 1.12268605 & .00049861 & -.00000080 & 248 & $1.72 \mathrm{E}-4$ \\
\hline 26 & 1.12268000 & .00049801 & -.00000080 & 434 & $1.72 \mathrm{E}-4$ \\
\hline 0 & 1.3 & .0 & .0 & 1 & $1.11 \mathrm{E} 2$ \\
\hline 62 & .99801208 & .00058158 & .00000023 & 1381 & $7.49 \mathrm{E}-1$ \\
\hline 105 & 1.23144216 & -.00020278 & .00000033 & 2133 & $2.85 \mathrm{E}-5$ \\
\hline
\end{tabular}

\section{Conclusion and discussion}

In order to recognize the specific nature of the identification problom it would be desirable to answer some open problems and to aim at further improvements of the algorithm. These are

1. For what cases and under what conditions is the existence and uniqueness of the solution provided?

2. What can be said about the size of the set of measured values $\bar{T}$ ?

3. What is the influence of perturbations in the field $\bar{T}$ on the solution?

4. Among functions of what form are we to seek the coefficient functions $c e$ or $\lambda$ ?

5. Addition of a regularization term (penalty function) and a corrector term to our functional in order

- to obtain a convex function and smoothing effect on the solution,

- to stick to the admissible domain of the unknown coefficient.

6. Choice of one or more functionals $E$.

This is to point out the necessity of continuation of further systematical theoretical and practical investigations.

\section{References}

[1] А. Н. Тихонов, В. Б. Гласко, Прияенение метода регуляриачии в нелипейных вадачаx, ЖК. вычисл. мат. Ік мат. физ. 5.3 (1965), 463-473.

[2] A. D. Iskeuderov, Multidimensional inverse problems for linear and quasilinear parabolio equations, Dokl. AN SSSR 225 (1975), 1005.

19 - Banach Center t. XIII 
[3] R. J. Lermit, Numerical methods for the identificalion of O.D.E's, SIAM J. Num. Anal. 12 (1975), 488.

[4] J. W. Mosevich, Identifying O.D.E's by Galerkin Method, Math. Computat. 31 (1977), 123.

Presented to the Semester

Computational Mathematics

Irebruary 20-May 30, 1980 